\title{
Obituary
}

\section{Eric Dunlop}

Eric Matheson Chase Dunlop, who died on 2 June 2000, aged 76 , will be best remembered as the person who first put chlamydial genital infection in the medical and general public domain. Through his pioneering work with Professor Barrie Jones and Dr M K Al-Hussaini at the Institute of Ophthalmology, London, in the 1960s, it was shown that Chlamydia trachomatis is a common pathogen of the genital tract. He was the first to isolate $C$ trachomatis from patients with non-gonococcal urethritis and to use a colposcope in a genitourinary medicine setting, which enabled him to describe the follicular changes in the cervix and rectum arising from such infection. He also postulated that $C$ trachomatis was a cause of pelvic inflammatory disease after noting that mothers whose babies had chlamydial ophthalmia neonatorum had symptoms and signs of salpingitis. These discoveries provided a fresh impetus into chlamydial research, culminating in the major advances in the diagnosis and control of chlamydial infection today. Chlamydia is now the commonest sexually transmitted bacterial

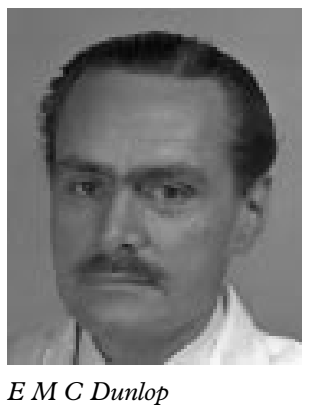

Eric Dunlop was born in Patagonia, Argentina, on 14 August 1923. He graduated from the Medical College of St Bartholomew's Hospital in 1945, obtained his MD in 1949 by thesis on the treatment of gonorrhoea with sulphonamides and with penicillin and was awarded a Charles Pfizer fellowship to the Johns Hopkins Hospital, Baltimore, in 1952. He was appointed consultant to the London Hospital in 1956 and to Moorfields Eye Hospital in 1964. He served on numerous committees and was honorary secretary and later president of the Medical Society for the Study of Venereal Diseases and assistant editor of the British fournal of Venereal Diseases. He was an excellent teacher who devoted much time to furthering recognition of his specialty and was among those who helped to set up the postgraduate course in sexually transmitted diseases and the diploma in venereology (now the diploma in genitourinary medicine) examinations. He enjoyed indoor bowls, gardening, music, ornithology, photography, and oil painting and used the latter during his retirement to benefit others by infection, has serious complications, and makes regular headline articles in newspapers and women's magazines. His other main research interest was in syphilis, where he studied corneal changes in congenital syphilis, the persistence of treponemes after treatment in the eye and cerebrospinal fluid, and treatment regimens for achieving treponemicidal levels of penicillin in the cerebrospinal fluid. having his paintings sold at auction for various charities. $\mathrm{He}$ was a family man and died on his 55 th wedding anniversary. He is survived by his wife Monica, their son and daughter.

Consultant in GU Medicine, The Ambrose King Centre, The Royal London Hospital, Whitechapel, London E1 1BB
BENG GOH 